across cultures and of genetic engineering appear (for no obvious reason) as appendices. There is no doubt that the book would be useful in providing students with an account of all these problems, and I will not take issue in a short review with any of the arguments used in their presentation. It is more appropriate, perhaps, to look briefly at the general approach and style of the book.

Having stated at the outset that medical ethics is part of applied moral philosophy the authors continue with some brief remarks on the historical background. Socrates, Plato, Aristotle, Hume and Kant fly by in less than four pages, including Kant's view of ethics in eight lines. Is it worth doing at such speed? I suspect that students can do little with this survey other than quote from it, encouraging the view that a fleeting reference from secondary sources to the great thinkers of the past is an essential part of applied moral philosophy. The subsequent discussion of utilitarianism and virtue ethics seems more pertinent, though 'the greatest good for the greatest number' (page 4) is unfortunately, like its better known variant, a misleading way of introducing the former. From here we are taken, via the Hippocratic oath, to certain principles that we should keep in mind, those concerning non-maleficence and beneficence, autonomy, professional integrity and justice. I can see no theoretical objection to the use of principles of this kind, though the reference to the role of the underlying value of care in cases of their conflict (page 12) is rather unclear. The practical problem is that the introduction of these terms at an early stage can have a stultifying effect on a student discussion that is happily proceeding in terms of harm, benefit, choice and fairness. I am not sure that the term 'techne' will help much either, especially when appearing from nowhere (page 15) with only the obscure expression 'skilled form of knowledge' by way of cursory explanation.

The above criticisms concern just the first chapter on the foundations of medical ethics. Not everyone will share them, and even those who do will find that the rest of the material is entirely worthwhile despite them. Here the relevant criticisms are those of style and are fairly minor. Sometimes the writing strays into a familiar academic wordiness ('healing process' for 'healing', 'family unit' for 'family', 'abortion procedures' for 'abortions') and occasionally into that of the more respectable leading article ('steps must be taken', 'sound and experienced opinion', 'widely recognized and respected') but although it doesn't sparkle, it is always thoroughly readable.

I noticed only two mistakes in this well produced book. There is a possibly confusing ambiguity in 'reduced opportunity costs' (page 77), since in the technical sense the opportunity costs increase. And in the discussion (page 135) of sexual misconduct in psychotherapy, an impeccably Freudian typo transforms 'therapist' into 'the rapist'.

HUGH UPTON

Centre for Philosophy and Health Care, University College of Swansea

\section{Ethical issues of molecular genetics in psychiatry}

Edited by R J Scram, V Bulyzhenkov, L Prillipke and Y Christen, Berlin, Springer-Verlag, 1991, 177 pages, DM 108

This volume contains papers presented and revised subsequent to discussion at a meeting to discuss the ethical issues arising from the application of molecular genetic technology to psychiatry, which was held in 1990 under the joint auspices of the World Health Organization and the IPSEN Foundation. The authors of the papers are drawn from a wide variety of disciplines, including psychiatry, genetics, religion and law. In the discussions of research techniques and the application of research findings to clinical issues, there is a presumption that the reader will be fully conversant with the relevant technical jargon and no attempt is made at translation for the lay reader or the genetically unsophisticated clinician. Although some of the papers such as that by Crow from London on the possibility of 'A single-gene locus for psychosis and intelligence' contain little ethical discussion, they provide the material for an understanding of other discussions of the complex ethical issues emerging in this rapidly advancing area.

Some themes recur. There is repeated reference to the success first in identifying the genetic pattern of the Medelian dominant inheritance of Huntington's Chorea and then in developing a test for the identification of carrier status. It is pointed out repeatedly that problems immediately flow from the fact that the test is not one giving total accuracy and that the handling of knowledge about carrier status imposes difficult ethical choices for a physician in possession of such information. However, such uncertainty of diagnosis and such difficulty over the handling of information in this relatively straightforward situation pales into insignificance beside the potential problems in terms of, for example, the appropriateness of termination of pregnancy or the control of the social exchange of information in respect of conditions such as schizophrenia, where a genetic cause is never likely to be more than an incomplete and partial explanation of the emergence of the condition and where it is unlikely that any certain predictions will be possible about the welfare of any individual carrying the relevant genes.

However, the problems attaching to the identification of the putative genetic substrate of the more common serious mental illnesses again fade into the background when consideration is given to the possibilities for genetic control of the more minor variations of temperament, intelligence and behaviour. In a very penetrating paper on 'The use of prenatal diagnosis for psychiatric diseases' Mattei from Marseilles sounds powerful notes of caution in respect of colluding with the parental search for the 'ideal child'. She mentions her experience in studying fetal material for evidence of Down's syndrome and discovering not uncommonly the presence of an extra $\mathrm{Y}$ chromosome. Despite reassuring the parents about the frequency of the latter abnormality and the lack of any close association with socially deviant behaviour, it is her experience that most parents seek out information from less well informed sources and nearly always seek a termination of pregnancy. Discussions of such issues are linked to the lack of clear dividing lines in psychiatry between normal and abnormal and the inherent dangers of becoming involved in the practice of eugenics.

In discussion of therapeutic possibilities of the new genetic technologies the potential dangers of introducing genetic material whose total possible range of action is unknown are highlighted. However, of ethically 
greater complexity is the possibility of introducing new genetic material into germ cells with potential consequences for untold future generations.

While this book is an excellent stimulant to the giving of careful consideration to the use to which the rapidly proliferating knowledge in this area could and should be put, it is short on detailed discussion and argument about how to resolve the issues which its many authors recognize. However, as a timely reminder of the problems soon to come it does excellent service.

CHRISTOPHER HOWARD Senior Lecturer, Department of Psychiatry, Royal Free Hospital School of Medicine, Rowland Hill Street, London NW3 2PF

\section{Teaching and learning nursing ethics}

\author{
Edited by Ursula Gallagher and $\mathrm{K} M$ \\ Boyd, London, Scutari Press, 1991, \\ 84 pages, $£ 8.99$.
}

This is an extremely useful work. It centres upon the findings of a postal survey concerned with the teaching of nursing ethics undertaken by the Royal College of Nursing and the Institute of Medical Ethics. The survey was used as the basis of the work of a multidisciplinary working party whose task it was to examine the meaning of ethical issues for nursing and to consider what is involved in the teaching of ethics to nurses, midwives and health visitors. The survey involved 500 respondents from nursing education establishments.

The book opens with a chapter which sets the background in terms of the 'meaning of ethics' and the main ethical principles which are the concern of nursing ethics. The central chapters of the book present the information from the survey. The editors are to be complimented upon achieving an extremely high return rate for survey work -98 per cent. The survey included 147 centres of education, identified through the National Boards for Nursing, Midwifery and Health Visiting. The findings are summarised in a concise and helpful way in the form of a short paragraph or small table for each of the 17 questions. This allows the reader to come quickly to grips with the findings.
The remaining chapters contain the discussion and some of the working party's suggestions for nursing ethics teaching. Particularly interesting is the chapter on the reasons for teaching nursing ethics, especially the discussion of the question of whether teaching of ethics should run through all of the course or be flagged up as the ethics component.

In all, this is a useful book and, whilst it will be of particular interest to those coming for the first time to the question of how to teach nursing ethics, it should not be overlooked by the 'old hands' as it provides some insightful discussion. The survey provides us with a particularly succinct and clear account of the views of those charged with the task of teaching ethics to nurses, midwives and health visitors.

\section{Department of Nursing Studies, University of Edinburgh, Edinburgh}

\section{The uses of philosophy}

Mary Warnock, Oxford, Blackwell, 1992, 243 pages, £11.95.

This wide-ranging collection of essays originated in public lectures. Its themes include the source and scope of human duties; the relationship between private morality, law and public goods; children's rights; policymaking in the absence of moral consensus; honesty in public life; standard-setting in broadcasting and in general education; philosophy in the school curriculum; the aims of education; the place of moral instruction; religious imagination; the contribution of memory to the maintenance of personal continuity; the reality of inner experience and its relation to personal identity, and the greater integration of the elderly through acknowledgement of them as deliberative agents

The range is impressive. On many topics Baroness Warnock speaks with an authority born of her considerable experience both as a participant in public reflection on moral and social issues, and as an educator. She also writes as a professional philosopher conscious of the theoretical complexities of the problems she addresses. The latter aspect of her competence is to the fore in only two or three of the chapters (those on personal continuity

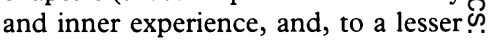
extent, that on religious imagination); but elsewhere she explicitly acknow- क् ledges philosophical difficulties, or writes in ways that signal her awareness of further complications.

It should be emphasised, however, that this is not a collection of $\frac{a}{\alpha}$ philosophical papers. Even where philosophical theory is operative, but $\overrightarrow{0}$ not dominant (as in the chapters mentioned), its touch is light. This is $\vec{\omega}$ no criticism. On the contrary, it is the very considerable merit of this book $\bar{\sigma}$ that it is not, and does not present itself as, exercises in 'applied philoso- $\bigcirc$ phy' of the sort now familiar. What we ? are offered are informed, thoughtful, $\overrightarrow{\vec{\theta}}$ modest (but not bland or uncontroversial) essays on issues of the first $\rightarrow$ importance. Although these are not philosophical papers, they are essays that only a philosopher could have $\overline{\mathbb{D}}$ written, and they are a credit to the $\vec{\bullet}$ British tradition of clearly focused and carefully measured thinking.

Anyone setting about writing on a moral problem would benefit from reading Warnock's introduction, as would editors and publishers considering submissions in the field of $\frac{\mathrm{D}}{\mathrm{D}}$ philosophy and public policy. She charts something of the recent history $\overrightarrow{\overrightarrow{0}}$ of philosophers' involvement in 3 practical affairs and sets out what she takes to be the proper role of critical thinking. The methodology of analysing claims and identifying the assumptions, principles and attitudes 0 that underlie them, is adverted to and 3 . effectively implemented throughout the collection. Warnock's technique $\frac{0}{3}$ bears some relation to Rawls's methods in political philosophy. She works towards values and principles that animate our intuitive judgements, brings them into contact with problem N cases and then moves to achieve some? degree of consistency. In effect she is $\mathbf{O}$ saying: 'We favour this policy here because we have a deep commitment $\sigma$ to the following value; that being so we cannot deny the pull of this or that claim in these other cases'.

There are objections to this style of argument. It is open to charges of begging the question against other $\frac{\text { () }}{\mathbb{D}}$ standpoints, of being unduly con-@ servative of inherited principles, even $\stackrel{\varnothing}{\varrho}$ of being anti-philosophical. More toб the point, given that the issues are controversial, there is the question of the ownership and content of the intuitions being articulated. Warnockㅡㅡ. belongs within the tradition of liberal utilitarianism - though more to the 